\title{
Bel Ağrısı Olan Hastalarda Huzursuz Bacak Sendromunun Risk Faktörleri ve Denge Üzerine Etkisi: Karşılaştırmalı Bir Çalışma
}

\section{Risk Factors of Restless Leg Syndrome in Patients with Low Back Pain and Its Effect on Balance: A Comparative Study}

\author{
Tuba Can Akman ${ }^{1}$, Fatih Tekin ${ }^{1 *}$ \\ ${ }^{1}$ Pamukkale Üniversitesi, Fizik Tedavi ve Rehabilitasyon Yüksekokulu, Denizli, Türkiye. \\ e-mail: tubacan@pau.edu.tr, fzt.ftekin@hotmail.com \\ ORCID: 0000-0001-5230-2009 \\ ORCID: 0000-0001-7829-7957 \\ *Sorumlu yazar/ Corresponding Author: Fatih Tekin \\ Gönderim Tarihi / Received: 10.04.2021 \\ Kabul Tarihi / Accepted: 30.04.2021 \\ DOI: $10.34087 /$ cbusbed. 912934
}

\begin{abstract}
Öz
Giriş ve amaç: Bu çalışmanın amacı, kronik bel ağrısı olan hastalarda Huzursuz Bacak Sendromu’nun (HBS) risk faktörlerini ve denge üzerine etkisini incelemektir.

Gereç ve yöntem: Pamukkale Üniversitesi Hastanelerine daha önce bel ağrısı şikayetiyle başvurmuş, dahil edilme kriterlerine uyan 98 olgu dâhil edilmiştir. Bu olgulardan HBS olan (HBS+) 66 olgu çalışma grubuna, HBS olmayan (HBS-) 32 olgu ise kontrol grubuna alınmıştır. Tüm olguların demografik bilgileri alınmış ve Uluslararası HBS Çalışma Grubu HBS Şiddet Skalası'na göre değerlendirmeleri yapılmıştır. Çalışma grubundaki olgulara ayrıca Aktivitelere Özgü Denge Güven Ölçeği (ADG-6) uygulanmıştır.

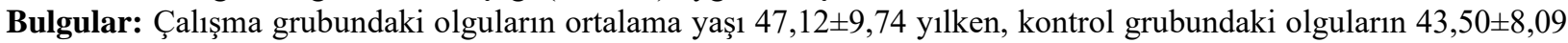
yıldı. Olguların \%67'si HBS+, \%33'ü HBS- olarak belirlenmiştir. HBS- olanların anlamlı şekilde ADG-6 skorlarının daha yüksek olduğu bulunmuştur $(\mathrm{p}<0,05)$. HBS+ olan katılımcıların HBS şiddetinin yaş $(r=0,439)$ ve Vücut Kitle İndeksi (VKİ) $(\mathrm{r}=0,406)$ ile pozitif yönde, eğitim süresi $(\mathrm{r}=-0,440)$ ve denge güven skoru $(\mathrm{r}=-0,467)$ ile ise negatif yönde orta düzeyde ve anlamlı ilişkisi tespit edilmiştir $(\mathrm{p}<0,05)$.

Sonuç: HBS, kronik non-spesifik bel ağrısı olan hastalarda denge güven skorunu azaltmaktadır. HBS, kadınlarda erkeklerden daha sık görülmektedir. HBS şiddeti ise cinsiyetten etkilenmezken yüksek VKİ ve ilerleyen yaş ile artmakta, eğitim düzeyinin artması ile azalmaktadır.
\end{abstract}

Anahtar Kelimeler: Bel ağrısı, Denge, Hhuzursuz bacak sendromu, Risk faktörleri

\footnotetext{
Abstract

Objective: The aim of this study is to examine the risk factors of Restless Leg Syndrome (RLS) and its effect on balance in patients with chronic low back pain.

Material and method: Ninety-eight cases who had previously applied to Pamukkale University Hospitals with complaints of low back pain and met the inclusion criteria were included. Among these cases, 66 cases with RLS (RLS+) were included in the study group, and 32 cases without RLS (RLS-) were included in the control group. The demographic information of all the cases was taken and evaluated according to the International Restless Legs Scale (IRLS). Activities-Specific Balance Confidence Scale (ABC Scale) was also applied to the subjects in the study group. The data obtained were analyzed with the t test.

Results: While the mean age of the cases in the study group was $47.12 \pm 9.74$ years, it was $43.50 \pm 8.09$ years in the control group. Cases' $67 \%$ were determined as RLS+, $33 \%$ as RLS-. It was found that those with RLS- had significantly higher ABC Scale scores $(\mathrm{p}<0.05)$. The RLS severity of participants with RLS+ was positively correlated with age $(r=0,439)$ and BMI $(r=0,406)$, and a moderate and significant correlation was found with the duration of education $(r=-0,440)$ and balance confidence score $(r=-0,467)(p<0.05)$.
} 
Conclusion: RLS reduces the balance confidence score in patients with chronic non-specific low back pain. RLS is more common in women than men. While RLS severity is not affected by gender, it increases with high BMI and advancing age, and decreases with increasing education level.

Key words: Balance, Low back pain, Restless leg syndrome, Risk factors

\begin{abstract}
1. Giriş
Huzursuz Bacak Sendromu (HBS), Willis-Ekbom hastalığı olarak da bilinen, bacakları hareket ettirme dürtüsü ile karakterize, genellikle rahatsız edici duyular ve uyku bozukluğunun eşlik ettiği kronik bir hareket bozukluğudur. Hastalığın prevalansı genel popülasyonda \%1-15 arasında değişmektedir [1].

Semptomların tarifi zor olmakla birlikte çoğunlukla bacaklarda engel olamadıkları hareket ettirme isteği, acı-yanma-karıncalanma şeklinde çok ağrılı olmayan, fakat oldukça rahatsız edici bir his şeklinde ifade etmektedirler [2]. $\mathrm{Bu}$ rahatsızlık istirahat sirasında ortaya çıkmakta, geceleri şiddetlenmekte ve genellikle uykudan uyandiran nitelikte olmakta, bu nedenle de kronik uyku bozukluğu, emosyonel strese yol açmaktadır. Doğru olarak tanı konulduğunda, semptomların giderilmesi ile efektif olarak tedavi edilebilmektedir [3].

Yaş, eğitim durumu, psikososyal faktörler, mesleki faktörler ve obeziteyi de içine alan birçok faktör kronik bel ağrısı gelişimi için risk oluşturmaktadır. Kronik bel ağrısının en önemli kaynağ Kronik bel ağrısı, iş kaybının en yaygın nedenlerinden biridir [4].

Literatürde kronik non-spesifik bel ağrısının çeşitli durumlarda denge becerilerinde kayba da yol açabileceği belirtilirken HBS tanılı hastalar için yapılmış bir araştırma yoktur [5].

Bu çalışmanın amacı, kronik bel ağrısı olan hastalarda HBS'nin risk faktörlerini ve denge üzerine etkisini incelemektir.
\end{abstract}

\section{Materyal ve Metot}

Bu çalışma, Aralık 2020-Mart 2021 tarihleri arasında Pamukkale Üniversitesi Fizik Tedavi ve Rehabilitasyon Yüksekokulu'nda yapılmıştır. Çalışmanın etik açıdan uygun olduğuna Pamukkale Üniversitesi Girişimsel Olmayan Araştırmalar Tıbbi Etik Kurulu'nun 60116787-020/73338 sayılı karar1 ile onay verilmiştir. Çalışmaya katılım gönüllülük esasına dayanmıştır ve tüm süreç boyunca Helsinki Deklarasyonu'na uygun hareket edilmiştir.

\section{1 Çalıșma Dizaynı}

Pamukkale Üniversitesi Hastanelerine daha önce bel ağrısı şikayetiyle başvurmuş, dâhil edilme kriterlerine uyan katılımcılar dâhil edilmiștir. Çalışma, Pamukkale Üniversitesi Fizik Tedavi ve Rehabilitasyon Yüksekokulu'nda yürütülmüştür. Katılımcıların öncelikle HBS durumu sorgulanmış ve buna göre gruplara ayrılmışlardır. Huzursuz Bacak Sendromu olan (HBS+) hastalar çalışma grubuna, HBS olmayanlar (HBS-) ise kontrol grubuna alınmıştır. tarafından tanımlanmıştır ve literatürde Johns Hopkins Ölçeği adı altında da kullanılmaktadır [8].

2.7 Istatistiksel Analiz
Ardından her iki gruba da değerlendirmeler yapılmış, elde edilen veriler analiz edilmiştir.

\subsection{Katılımcilar}

Çalışma grubu için dâhil edilme kriterleri; Uluslararası HBS Çalışma Grubu Tanı Kriterlerine uyan, en az 1 yıldır kronik bel ağrısı olan, 30 yaş üstü olan, tanısı konmuş nörolojik ya da ortopedik hastalığı olmayan ve iletişim kurabilen katılımcılar alınmıştır. Kontrol grubu için ise Uluslararası HBS Çalışma Grubu Tanı Kriterlerini taşımamak olarak belirlemiştir. Geriye kalan kriterler, çalışma grubu ile aynı tutulmuştur. Çalışmaya katılım gönüllülük esasına dayanmış ve anketler Covid-19 pandemisi nedeniyle telefon yoluyla ve çeşitli online yöntemlerle yapılmıştır.

\subsection{Demografik Veri Formu}

Katılımcıların yaş, cinsiyet, boy, kilo, Vücut Kitle İndeksi (VKİ), bel ağrısı yaşadıkları süre (yıl), eğitim durumu gibi bilgileri alınarak demografik veri formlarına kaydedilmiștir.

\subsection{Uluslararası HBS Çalışma Grubu Tanı Kriterleri}

HBS tanısı için belirtilen 4 standart tarama sorusu sorulmuştur. $\mathrm{Bu}$ soruların (huzursuzluk hissi olup olmadığ 1 , istirahatte kötüleşip kötüleşmediği, akşam saatlerinde ortaya çıkma ve hareket ile ortadan kalkıp kalkmadığını sorgulamakta) tamamını 'evet' olarak yanıtlayan bireyler HBS+ olarak kabul edilmiştir [1]. 2.5.Aktivitelere Özgü Denge Güven Ölçeği (ADG-6) Performans ilişkili bir denge değerlendirme ölçeğidir. Hastaların ev içinde ve ev dışında belirtilen altı aktiviteyi ne kadar güvenle yapabildiklerini, 0 (güvensiz) ile 100 (tamamen güvenli) arasında değerlendirmeleri esasına dayanan bir ankettir. Hastalar tarafindan doldurulan anket sonucunda oluşan toplam skor (0-600) 16'ya bölünerek elde edilir. Yüksek puan güvenin daha fazla olduğuna işaret eder. ADG-6 skalada 60'ın altında skorlar, klinik olarak anlamlı bulunmuştur ve yaşlılarda yüksek fonksiyonel durumda olan bireyler ile düşük fonksiyonel durumdaki bireyleri ayırmak için kullanışlı bir araçtır. Diğer denge testleri ve düşmeler ile güçlü korelasyona sahip olan ADG-6 skalası, kısa ve hızlı uygulanan bir form olması sebebiyle kullanışlı bir ölçek olarak değerlendirilmektedir [6]. Ölçeğin Türkçe geçerlik ve güvenilirlik çalışması mevcuttur [7].

2.6.Uluslararası HBS Çalışma Grubu HBS Şiddet Skalasl (IRLSS)

HBS'nin şiddetini belirlemeye yönelik olarak hastalığın tipik belirtileri üzerine sorulan, her biri 0-4 arası derecelendirilmiş 10 sorudan oluşmaktadır. 0-10 puan hafif, 11-20 puan orta, 21-30 puan ciddi, 31-40 puan çok ciddi HBS şeklinde değerlendirilmiştir. Bu skala John Hopkins

Literatürden edinilen bilgiler doğrultusunda yapılan güç analizinde; incelenecek değişkenler arasındaki ilişkinin etki büyüklüğünün orta düzeyde $(\mathrm{r}=0.4)$ 
olabileceği varsayılarak, çalışmaya en az 90 birey dahil edildiğinde $\% 95$ güven düzeyinde $\% 90$ güç elde edilebileceği hesaplanmıştır. Veriler SPSS 25 (IBM SPSS Statistics 25 software (Armonk, NY: IBM Corp.)) paket programıla analiz edilmiştir. Sürekli değişkenler ortalama \pm standart sapma ve kategorik değişkenler sayı ve yüzde olarak verilmiştir. Sürekli değişkenlerin arasındaki ilişkiler Spearman korelasyon analiziyle, bağımsız gruplar arasındaki farklar ise t testi ile incelenmiştir. Spearman korelasyon katsayısı " $r$ " 0.2-0.4 arasında ise zayıf, 0.4-0.6 arasında ise orta, 0.6-
0.8 arasında ise yüksek ve $>0.8$ ise çok yüksek korelasyon olarak kabul edilmiştir.

\section{Bulgular ve Tartışma}

Çalışmaya toplamda 98 kronik bel ağrılı birey alınmış, bu bireylerin \%67' sinde HBS+ olduğu tespit edilmiştir. Gruplar arasında yaş, VKİ ve bel ağrısı süresi yönünden fark bulunmamıştır $(\mathrm{p}>0,05)$. Huzursuz bacak sendromlu katılımcıların \%68'i kadındır (Tablo 1). Gruplar arasinda farkın olmaması, yapilan değerlendirmelerin etkilenmemesi açısından önemlidir.

Tablo 1. Katılımcıların Demografik Verileri

\begin{tabular}{|c|c|c|c|c|c|c|c|}
\hline \multirow{2}{*}{\multicolumn{2}{|c|}{ Demografik Veriler }} & \multicolumn{2}{|c|}{ HBS+ } & \multicolumn{2}{|c|}{ HBS- } & \multirow{2}{*}{\multicolumn{2}{|c|}{$* p$}} \\
\hline & & \multicolumn{2}{|c|}{$\mathbf{X} \pm \mathbf{S D}$} & \multicolumn{2}{|c|}{$\mathbf{X} \pm \mathbf{S D}$} & & \\
\hline \multicolumn{2}{|l|}{ Yaş (yıl) } & \multicolumn{2}{|c|}{$47,12 \pm 9,74$} & \multicolumn{2}{|c|}{$43,50 \pm 8,09$} & \multicolumn{2}{|c|}{0,222} \\
\hline \multicolumn{2}{|l|}{ VKİ $\left(\mathrm{kg} / \mathrm{m}^{2}\right)$} & \multicolumn{2}{|c|}{$26,78 \pm 4,57$} & \multicolumn{2}{|c|}{$25,90 \pm 5,46$} & \multicolumn{2}{|c|}{0,231} \\
\hline \multicolumn{2}{|c|}{ Eğitim Süresi (yıl) } & \multicolumn{2}{|c|}{$8,92 \pm 4,20$} & \multicolumn{2}{|c|}{$10,75 \pm 4,45$} & \multicolumn{2}{|c|}{0,566} \\
\hline \multirow{2}{*}{\multicolumn{2}{|c|}{ Bel Ağrısı Süresi (yıl) }} & \multicolumn{2}{|c|}{$5,92 \pm 7,30$} & \multicolumn{2}{|c|}{$4,75 \pm 5,15$} & \multicolumn{2}{|c|}{0,176} \\
\hline & & $\mathbf{n}$ & $\%$ & $\mathbf{n}$ & $\%$ & Toplam & $* p$ \\
\hline \multirow{2}{*}{ Cinsiyet } & Kadın & 45 & 68,2 & 20 & 62,5 & 65 & \multirow{2}{*}{0,348} \\
\hline & Erkek & 21 & 31,8 & 12 & 37,5 & 33 & \\
\hline \multirow{2}{*}{$\begin{array}{l}\text { Medeni } \\
\text { Durum }\end{array}$} & Evli & 55 & 83,3 & 25 & 78,1 & 80 & \multirow{2}{*}{0,417} \\
\hline & Bekar & 11 & 16,7 & 7 & 21,9 & 18 & \\
\hline
\end{tabular}

HBS+: Huzursuz Bacak Sendromu olan katılımcılar, HBS-: Huzursuz Bacak Sendromu olmayan katılımcılar, VKİ: Vücut Kitle İndeksi FTR: Fizik Tedavi ve Rehabilitasyon, X: Ortalama, SD: Standart Sapma, p: Anlamlılık Değeri $(<0,05)$, *: Bağımsız Gruplar t Testi

Katılımcıların denge güven skorları karşılaştırıldığında, HBS- olanların anlamlı şekilde ADG-6 skorlarının daha yüksek olduğu bulunmuştur

( $\mathrm{p}<0,05)$ (Tablo 2). HBS+ olan katılımcıların HBS şiddetlerine göre dağılımı Tablo 3 'te verilmiştir.

Tablo 2. Grupların denge güven skorları ve karşılaştırması

\begin{tabular}{|c|c|c|c|c|c|c|}
\hline ADG-6 & $\mathbf{n}$ & $\mathbf{X} \pm \mathbf{S D}$ & $\mathbf{t}$ & Ortalama Fark & Standart Hata & $* \boldsymbol{p}$ \\
\hline HBS+ & 66 & $62,35 \pm 18,60$ & $-1,569$ & $-6,18$ & 3,93 & 0,048 \\
\hline HBS- & 32 & $68,53 \pm 17,55$ & & & \\
\hline
\end{tabular}

ADG-6: Aktivitelere Özgü Denge Güven Ölçeği, HBS+: Huzursuz Bacak Sendromu olan katılımcılar, HBS-: Huzursuz Bacak Sendromu olmayan katılımcılar, X: Ortalama, SD: Standart Sapma, t: Test İstatistiği, $p<0,05$, *: Băğıssı Gruplar t Testi

Tablo 3. Grupların denge güven skoru dağılımları

\begin{tabular}{|c|c|c|}
\hline IRLSS & $\mathbf{n}$ & $\mathbf{\%}$ \\
\hline Hafif & 21 & 31,8 \\
\hline Orta & 24 & 36,4 \\
\hline Ciddi & 19 & 28,8 \\
\hline Çok Ciddi & 2 & 3,0 \\
\hline
\end{tabular}

IRLSS: Uluslararası HBS Çalışma Grubu HBS Şiddet Skalası 
HBS+ olan katılımcıların HBS şiddetinin yaş $(\mathrm{r}=0,439)$ ve VKİ $(r=0,406)$ ile pozitif yönde, eğitim süresi $(r=-$ $0,440)$ ve denge güven skoru $(r=-$
$0,467)$ ile ise negatif yönde orta düzeyde ve anlamlı ilişkisi tespit edilmiştir $(\mathrm{p}<0,05)$ (Tablo 4).

Tablo 4. HBS şiddetinin diğer parametrelerle ilişkisi

\begin{tabular}{|c|c|c|c|c|c|c|}
\hline \multicolumn{2}{|c|}{} & Yaş (yıl) & VKİ (kg/m²) & $\begin{array}{c}\text { Eğitim Süresi } \\
(\mathbf{y l l})\end{array}$ & $\begin{array}{c}\text { Bel Ağrısı Süresi } \\
\text { (yıl) }\end{array}$ & ADG-6 \\
\hline \multirow{3}{*}{ IRLSS } & $\mathrm{r}$ & $0,439^{*}$ & $0,406^{*}$ & $-0,440^{*}$ & 0,103 & $-0,467^{*}$ \\
\cline { 2 - 7 } & $\mathrm{p}$ & 0,018 & 0,042 & 0,017 & 0,312 & 0,001 \\
\hline
\end{tabular}

IRLSS: Uluslararası HBS Çalışma Grubu HBS Şiddet Skalası, VKİ: Vücut Kitle İndeksi, ADG-6: Aktivitelere Özgü Denge Güven Ölçeği, $p<0,05$, r: Spearman Korelasyon Analizi

Kronik bel ağrısı olan hastalarda HBS'nin denge üzerine etkisini incelemek amacıyla yaptığımız bu karşılaştırmalı çalışmada; HBS+ olan katılımcıların denge güven skorlarının anlamlı ölçüde daha düşük olduğunu, ayrıca HBS şiddetinin bel ağrısı süresinden anlamlı ölçüde etkilenmediğini ancak yaş, VKİ ve eğitim süresi gibi faktörler ile HBS şiddeti arasında anlamlı bir ilişki bulunduğunu tespit ettik.

Hem HBS+ hem de HBS- olan katılımciların denge güven skorlarının 60'ın üzerinde olup denge bakımından katılımcıların yüksek fonksiyonel düzeyde olduğunu göstermektedir. Ancak HBS- olan katılımcıların denge güven skorları HBS+ olanlardan anlamlı ölçüde yüksektir. Bir başka deyişle HBS, denge güven skorunu azaltmakta, ancak yine de bireyin yüksek fonksiyonel düzeyin altına inmesine sebep olmamaktadır.

Högl ve arkadaşları 2005 yılında 50-89 yaş arası 701 katılımcı (E: $335 \mathrm{~K}: 366$ ) ile yaptıkları bir araştırmada popülasyonda HBS görülme sıklığını $\% 10,6$ bulmuștur. Erkeklerde bu oran \%6,6 iken kadınlarda \%14,2 bulunmuştur [9]. 65-83 yaş arası popülasyonda yapılan bir başka çalışmada da kadın/erkek oranı 2:1 bulunmuştur [10]. Bizim çalışmamızdaki popülasyon bu çalışmalardan farklı olsa da yine kadın HBS+ kişi sayısı daha yüksek ve yine kadın/erkek oranı 2:1 bulunmuștur.

Çalışmamızın sonuçlarına göre katılımcıların deneyimlediği bel ağrısının ne kadar zamandır devam ettiği HBS şiddetini etkilememektedir. Diğer yandan, yaş ilerledikçe HBS şiddeti artmaktadır. HBS'ye sebep olan anatomik ve fizyolojik deformitelerin yaşlanmayla birlikte ilerlemesi bu durumun muhtemel nedenidir.

Çalışmamızın sonuçlarına paralel olarak güncel literatürde de HBS'nin yaşla birlikte arttığı gösterilmiştir [11, 12, 13]. Bununla birlikte genç nüfusta daha fazla HBS+ birey görüldüğünü, ancak bu durumun yaşlı popülasyondaki tanı koyma sıklığının düşük olmasından kaynaklandığını belirten çalışmalar da mevcuttur [10]. HBS prevalansını araştıran bir başka çalışmaya göre ise 20-29 yaş grubunda HBS prevalansı $\% 1$ iken, 70-89 yaş grubunda bu oran \%4'e çıkmaktadır [14]. Amerika [15] ve İsveç’te [16] yapılan araştırmalara göre artan yaşla birlikte HBS frekansı da artmaktadır. Almanya [10], Fransa [17], Güney Kore [18] ve Brezilya'da [19] yapılan araştırmalar da bu sonuçları desteklemektedir. Tayvan [20] ve Japonya'da [21] yapılan araştırmalarda ise yaşlılardaki HBS prevalansı genç popülasyonla anlamlı bir farklılık göstermemektedir [22].

Güncel literatürde bel ağrısının HBS üzerine etkisini araştıran herhangi bir araştırma yoktur. Çalışmamızın sonuçları bu anlamda ilktir. Ancak HBS+ olan bireylerde bel ağrısı başta olmak üzere ağrılı sendromların daha sık izlendiğini gösteren çalışmalar mevcuttur [11].

Bireyin eğitim düzeyi arttıkça HBS şiddeti azalmaktadır. Eğitim düzeyi yüksek bireylerin HBS'yi agreve eden faktörler hakkında daha bilinçli olması ve muhtemelen nispeten daha az fiziksel güç gerektiren işlerde çalışmaları nedeniyle bu sonuç meydana gelmiş olabilir. Bu teoriyi destekler şekilde güncel literatürde düşük eğitim düzeyinin düşük sosyo-ekonomik statüyle, düşük sosyo-ekonomik statünün de HBS prevalansı ile yakından ilişkili olduğu gösterilmiştir [23].

Çalışmamızın sonuçlarını destekleyecek şekilde Szentkiralyi ve arkadaşlarının 2009'da yaptığ 1 bir araştırmada da eğitim düzeyi daha yüksek olan bireylerde HBS görülme oranının azaldığı, görülen bireylerde ise şiddetinin daha az olduğu bulunmuştur [24]. HBS'ye dair risk faktörlerini inceleyen bir başka araştırmada da buna paralel sonuçlar çıkmış, ayrıca HBS ile eğitim düzeyi arasındaki bu ilişkinin cinsiyet, yüksek komorbidite oranları ve parite (doğum sayısı) gibi faktörlerden de bağımsız olduğu tespit edilmiştir [25].

VKİ'nin artması HBS şiddetini artırmaktadır. Yüksek VKİ alt ekstremitelere daha fazla yük binmesine sebep olacağından HBS şiddetinin artması da beklenen bir sonuç olup buradan, HBS+ olan bireylere kilo verme önerisi yapılmasının yerinde olacağı sonucu çıkmaktadır.

Güncel literatürde de çalışmamızın sonuçlarını destekler şekilde VKİ arttıkça HBS şiddetinin arttığını ve obez popülasyonda $\mathrm{HBS}+$ bireylerin daha s1k 
görüldüğünü belirten çalışmalar mevcuttur [26, 27]. Obezite ve HBS'nin ilişkisinin altında yatan nedenler belirsizliğini korurken, her ikisinin de hipertansiyon, yüksek kolesterolü ve diyabet gibi ortak risk faktörlerine sahip olmaları ve obezite hastalarında görülmesi muhtemel vasküler yaralanmalar olası mekanizmalar olarak bildirilmiştir [28]. Obezite ve HBS'nin ilişkisi üzerine yapılmış bir meta-analiz çalışmasına göre de obez yetişkinlerde HBS görülme ihtimali daha yüksek olup kadınlar daha yüksek risk altındadır. Adölesanlar için ise daha fazla çalışmaya ihtiyaç vardır [29].

HBS şiddeti ile denge güven skoru arasında negatif yönde bir ilişki mevcuttur. HBS şiddeti arttıkça bireyler denge yönünden kendilerini daha güvensiz hissetmektedir. Çalışmamızdaki HBS+ popülasyonun ortalama denge güven skoruna bakıldığında popülasyonun hâlen yüksek fonksiyonel düzeyde olduğu görülmektedir. Ancak, HBS+ olarak geçirilen zaman arttıkça bireylerin denge güven skorlarının da düşük fonksiyonel düzeye inebileceği öngörülebilmektedir.

Güncel literatürde HBS şiddeti ile denge güven skoru arasındaki ilişkiyi araştıran bir çalışma bulunmamaktadır. Çalışmamızın sonuçları bu alanda ilktir.

\section{Sonuçlar}

HBS, kronik non-spesifik bel ağrısı olan hastalarda denge güven skorunu azaltmaktadır. HBS, kadınlarda erkeklerden daha sık görülmektedir. HBS şiddeti ise cinsiyetten etkilenmezken yüksek VKİ ve ilerleyen yaş ile artmakta, eğitim düzeyinin artması ile azalmaktadır. Çalışmaya dâhil edilen katılımcıların cinsiyet, medeni durum, meslek grubu ve alınan tedavi gibi parametreler açısından farklı grupları içermesi bu çalışmanın güçlü yanıdır. Kullanılan değerlendirme yöntemlerinin subjektif olması ise çalışmanın limitasyonudur.

HBS'nin sebep olabileceği bozuklukları araştıran daha geniş ve daha spesifik popülasyonlarda yapılacak yeni çalışmalara ihtiyaç vardır.

\section{Referanslar}

1. Filiz, M.B, Çakır, T, Güncel Tanı Kriterleri ile Huzursuz Bacak Sendromu, Türk Osteoporoz Dergisi, 2015, 21(2), 87-95.

2. Montplaisir, J, Boucher, S, Nicolas, A, Lesperance, P, Gosselin, A Rompré, P, Lavigne, G, Immobilization tests and periodic leg movements in sleep for the diagnosis of restless leg syndrome, Movement Disorders: Official Journal of the Movement Disorder Society, 1998, 13(2), 324-329.

3. Moreira, N.C.V, Damasceno, R.S, Medeiros, C.A.M, De Bruin, P.F.C, Teixeira, C.A.C, Horta, W.G, De Bruin, V.M.S, Restless leg syndrome, sleep quality and fatigue in multiple sclerosis patients, Brazilian Journal of Medical and Biological Research, 2008, 41(10), 932-937.

4. Ay, S, Evcik, D, Kronik bel ağrılı hastalarda depresyon ve yaşam kalitesi, Yeni Tip Dergisi, 2008, 25(4), 228-231.

5.Mientjes, M.I.V, Frank, J.S, Balance in chronic low back pain patients compared to healthy people under various conditions in upright standing, Clinical Biomechanics, 1999, 14(10), 710-716.
6. Powell, L.E, Myers, A.M, The activities-specific balance confidence (ABC) scale, The Journals of Gerontology Series A: Biological Sciences and Medical Sciences, 1995, 50(1), M28-M34.

7. Ayhan, C, Büyükturan, Ö, Kırdı, N, Yakut, Y, Güler, C,, The Turkish Version of The Activities Specific Balance Confidence (Abc) Scale: Its Cultural Adaptation, Validation and Reliability in Older Adults, Turkish Journal of Geriatrics, 2014, 17(2), 157-163.

8. Allen, R.P, Picchietti, D.L, Garcia-Borreguero, D, Ondo, W.G, Walters, A.S, Winkelman, J.W, Restless legs syndrome/WillisEkbom disease diagnostic criteria: updated International Restless Legs Syndrome Study Group (IRLSSG) consensus criteriahistory, rationale, description, and significance, Sleep Medicine, 2014, 15(8), 860-873.

9. Högl, B, Kiechl, S, Willeit, J, Saletu, M, Frauscher, B, Seppi, K, Poewe, W. Restless legs syndrome: a community-based study of prevalence, severity, and risk factors, Neurology, 2005, 64(11), 1920-1924

10. Rothdach, A.J, Trenkwalder, C, Haberstock, J, Keil, U, Berger, K, Prevalence and risk factors of RLS in an elderly population: the MEMO study, Neurology, 2000, 54(5), 1064-1068.

11. Allen, R.P, Picchietti, D, Hening, W.A, Trenkwalder, C, Walters, A.S, Montplaisi, J, Restless legs syndrome: diagnostic criteria, special considerations, and epidemiology: a report from the restless legs syndrome diagnosis and epidemiology workshop at the National Institutes of Health, Sleep Medicine, 2003, 4(2), 101-119.

12. Merlino, G, Valente, M, Serafini, A, Gigli, G.L, Restless legs syndrome: diagnosis, epidemiology, classification and consequences, Neurological Sciences, 2007, 28(1), S37-S46.

13. Hening, W, Allen, R.P, Tenzer, P, Winkelman, J.W, Restless legs syndrome: demographics, presentation, and differential diagnosis, Geriatrics, 2007, 62(9), 26-29.

14. Hening, W, Walters, A.S, Allen, R.P, Montplaisir, J, Myers, A, Ferini-Strambi, L, Impact, diagnosis and treatment of restless legs syndrome (RLS) in a primary care population: the REST (RLS epidemiology, symptoms, and treatment) primary care study, Sleep Medicine, 2004, 5(3), 237-246.

15. Phillips, B, Hening, W, Britz, P, Mannino, D, Prevalence and correlates of restless legs syndrome: results from the 2005 National Sleep Foundation Poll, Chest, 2009, 129(1), 76-80.

16. Ulfberg, J, Bjorvatn, B, Leissner, L, Gyring, J, Karlsborg, M, Regeur, L, Partinen, M, Comorbidity in restless legs syndrome among a sample of Swedish adults, Sleep Medicine, 2007, 8(7-8), 768-772.

17. Celle, S, Roche, F, Kerleroux, J, Thomas-Anterion, C, Laurent, B, Rouch, I, Sforza, E, Prevalence and clinical correlates of restless legs syndrome in an elderly French population: the synapse study, Journals of Gerontology Series A: Biomedical Sciences and Medical Sciences, 2010, 65(2), 167-173.

18. Kim, K.W, Yoon, I.Y, Chung, S, Shin, Y.K, Lee, S.B, Choi, E.A Kim, J.M, Prevalence, comorbidities and risk factors of restless legs syndrome in the Korean elderly population-results from the Korean Longitudinal Study on Health and Aging, Journal of Sleep Research, 2010, 19(1-Part-I), 87-92.

19. Dantas, F.G, Medeiros, J.L.A, Farias, K.S, Ribeiro, C.D, Restless legs syndrome in institutionalized elderly, Arquivos de Neuropsiquiatria, 2008, 66(2B), 328-330.

20. Chen, W.C, Lim, P.S, Wu, W.C, Chiu, H.C, Chen, C.H, Kuo, H.Y, Woods, H.F, Sleep behavior disorders in a large cohort of Chinese (Taiwanese) patients maintained by long-term hemodialysis, American Journal of Kidney Diseases, 2006, 48(2), 277-284.

21. Tsuboi, Y, Imamura, A, Sugimura, M, Nakano, S, Shirakawa, S, Yamada, T, Prevalence of restless legs syndrome in a Japanese elderly population, Parkinsonism \& Related Disorders, 2009 15(8), 598-601.

22. Yeh, P, Walters, A.S, Tsuang, J.W, Restless legs syndrome: a comprehensive overview on its epidemiology, risk factors, and treatment, Sleep and Breathing, 2012, 16(4), 987-1007.

23. Phillips, B, Young, T, Finn, L, Asher, K, Hening, W.A, Purvis, C, Epidemiology of restless legs symptoms in adults, Archives of Internal Medicine, 2000, 160(14), 2137-2141.

24. Szentkiralyi, A, Molnar, M.Z, Czira, M.E, Deak, G, Lindner, A.V Szeifert, L, Novak, M, Association between restless legs syndrome and depression in patients with chronic kidney disease, Journal of Psychosomatic Research, 2009, 67(2), 173-180. 
25. Berger, K, Luedemann, J, Trenkwalder, C, John, U, Kessler, C, Sex and the risk of restless legs syndrome in the general population, Archive of Internal Medicine, 2004, 164(2), 196-202.

26. Gao, X, Schwarzschild, M.A, Wang, H, Ascherio, A, Obesity and restless legs syndrome in men and women, Neurology, 2009, 72(14), 1255-1261.

27. Zobeiri, M, Shokoohi, A, Restless leg syndrome in diabetics compared with normal controls, Sleep Disorders, 2014, 2014, 1-4.

28. Winter, A.C, Schürks, M, Glynn, R.J, Buring, J.E, Gaziano, J.M, Berger, K, Kurth, T, Vascular risk factors, cardiovascular disease, and restless legs syndrome in women, The American Journal of Medicine. 2013, 126(3), 220-227.

29. Lin, S, Zhang, H, Gao, T, Zhong, F, Sun, Y, Cai, J, Ma, A, The association between obesity and restless legs syndrome: A systemic review and meta-analysis of observational studies, Journal of Affective Disorders, 2018, 235, 384-391.

http://edergi.cbu.edu.tr/ojs/index.php/cbusbed isimli yazarın CBU-SBED başlıklı eseri bu Creative Commons Alıntı-Gayriticari4.0 Uluslararası Lisansı ile lisanslanmıştır.
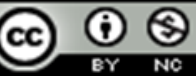